Vitamin A, nutrition, and health values of algae: Spirulina, Chlorella, and Dunaliella

\author{
Tang, G ; Suter, P M
}

\begin{abstract}
Spirulina, chlorella, and dunalliella are unicellular algae that are commercially produced worldwide. These algae are concentrated sources of carotenoids (especially provitamin A carotenoids) and other nutrients, such as vitamin B12. Their health benefits as a complementary dietary source for macro and micro nutrients have been studied and confirmed in various populations. The safety of human consuming these algae and products derived from these algae by humans has been widely studied. It is generally concluded that these algae and its products are safe if cultivated properly in a non-contaminated environment, and if consumed in moderation.
\end{abstract}

DOI: https://doi.org/10.6000/1927-5951.2011.01.02.04

Posted at the Zurich Open Repository and Archive, University of Zurich ZORA URL: https://doi.org/10.5167/uzh-61173

Journal Article

Published Version

Originally published at:

Tang, G; Suter, P M (2011). Vitamin A, nutrition, and health values of algae: Spirulina, Chlorella, and Dunaliella. Journal of Pharmacy and Nutrition Sciences, 1(2):111-118.

DOI: https://doi.org/10.6000/1927-5951.2011.01.02.04 


\title{
Vitamin A, Nutrition, and Health Values of Algae: Spirulina, Chlorella, and Dunaliella
}

\author{
Guangwen Tang ${ }^{1, *}$ and Paolo M. Suter ${ }^{2}$ \\ ${ }^{1}$ Jean Mayer USDA Human Nutrition Research Center on Aging at Tufts University, 711 Washington Street, \\ Boston, MA 02111, USA \\ ${ }^{2}$ University Hospital, Department of Medicine, KPIM, Raemistrasse 100, 8091 Zurich, Switzerland
}

\begin{abstract}
Spirulina, chlorella, and dunalliella are unicellular algae that are commercially produced worldwide. These algae are concentrated sources of carotenoids (especially provitamin A carotenoids) and other nutrients, such as vitamin B12. Their health benefits as a complementary dietary source for macro and micro nutrients have been studied and confirmed in various populations. The safety of human consuming these algae and products derived from these algae by humans has been widely studied. It is generally concluded that these algae and its products are safe if cultivated properly in a non-contaminated environment, and if consumed in moderation.
\end{abstract}

Keywords: Algae, spirulina, chlorella, dunalliella, nutrition, and functional foods.

\section{INTRODUCTION}

Algae have been cultured and used as a human food for many years. In the last four decades, the commercial production of micro algae that are rich in provitamin A carotenoids has been mainly focused on spirulina, chlorella, and dunaliella [1]. These micro algae are the cell organisms that can easily grow in either fresh water or sea water. In addition to high levels of provitamin A, dried micro algae can provide various other nutrients including proteins, minerals, vitamins, and antioxidants. World production of consumable algae and algae products to be used as dietary supplements, food additives, functional foods, and medicines has reached thousands of tons per year [2-4]. Because of their potential use as biofuel, production will undoubtedly increase. However, many of the nutritional intervention studies for nutritional rehabilitation of malnutrition are of poor-methodological quality and have to be interpreted with caution [5]. In this article, recent progresses on the provitamin A value of these algae and their health benefits for humans will be reviewed.

\section{Spirulina (Athrospira platensis and Arthrospira maxima) Nutrient Content}

The microorganism called "spirulina" was so named this because of its spiral filament-like appearance under the microscope (and is classified as cyanobacterium). The nutritional composition of spirulina may vary according to the growing conditions.

*Address corresponding to this author at the Jean Mayer USDA Human Nutrition Research Center on Aging at Tufts University, 711 Washington Street, Boston, MA 02111, USA; Tel: +617-556-3236; Fax: +617-556-3344; E-mail: Guangwen.Tang@Tufts.edu
For example, the iodine content will vary as a function when the spirulina is grown in sea water vs. fresh water. The nutritional composition of commercially available dried powdered spirulina grown in fresh water is summarized in Table 1. It should be noted that the cell wall of spirulina is composed of protein, carbohydrates and fat and not from indigestible cellulose. Therefore, the bioavailability of nutrients from spirulina might be more than from other food sources, especially plant food sources [6].

There are substantial amounts of vitamin B12 in spirulina (also in chlorella) algae tablets. The bioavailability of vitamin B12-compounds from spirulina (and chlorella) was evaluated using vitamin B12deficient rats [7]. The results suggested that algal vitamin B12 is a bioavailable source for mammals. However, pseudovitamin B12 (an inactive corrinoid) which predominated in the spirulina tablets are not suitable for use as a vitamin B12 source [8].

Spirulina has an exceptionally high protein content (on the order of $60-70 \%$ of its dry weight), of which $90 \%$ is digestible. Spirulina contains all the essential amino acids in fairly high amounts, but the amount of the sulphur amino acids is low [9]. The biological value of algae protein varies according to the algae species [10]. Based on limited scientific evidence available, spirulina might be a promising source of protein for human nutriture especially in the situation of protein malnutrition. Athrospira platensis was originally collected from Lake Chad, Africa while Arthrospira maxima was originally collected from Lake Texcoco, Mexico [6]. This alga can also be produced, processed, and distributed, on a small scale, by local farming 
networks in less developed countries. Village ponds and lakes [1], or land with soil conditions unsuitable for conventional crops [11] can be used.

Table 1: Nutritional Composition of Commercially Produced Dried Spirulina Powder (per $100 \mathrm{~g}$ ) Adapted from [Reference: A. Belay. Spirulina (Arthrospira): Production and Quality Assurance. In: Spirulina in Human Nutrition and Health. ME Gershwin and A Belay. CRC Press, Boca Raton, FL, USA, 2008].

\begin{tabular}{|c|c|}
\hline Energy Content & $373 \mathrm{kcal}$ \\
\hline Total Fat & $4.3 \mathrm{~g}$ \\
\hline - saturated fat & 1.95 \\
\hline - PUFA & 1.93 \\
\hline - MUFA & 0.26 \\
\hline - Cholesterol & $<0.1$ \\
\hline - gamma-Linolenic acid (GLA) & $1080 \mathrm{mg}$ \\
\hline Carbohydrate & $17.8 \mathrm{~g}$ \\
\hline Protein & $63 \mathrm{~g}$ \\
\hline Vitamin A (as beta-Carotene) & $352,000 \mathrm{IU}$ \\
\hline Total carotenoids (mean) & $504 \mathrm{mg}$ \\
\hline - $\beta$-carotene (mean) & $211 \mathrm{mg}$ \\
\hline - Zeaxanthin & $101 \mathrm{mg}$ \\
\hline Vitamin $\mathrm{K}$ & $1090 \mu \mathrm{g}$ \\
\hline Vitamin B1 (Thiamine HCL) & $0.5 \mathrm{mg}$ \\
\hline Vitamin B2 & $4.5 \mathrm{mg}$ \\
\hline Niacin & $14.9 \mathrm{mg}$ \\
\hline Vitamin B 6 (Pyridoxine HCL) & $0.96 \mathrm{mg}$ \\
\hline Vitamin B12 & $162 \mu \mathrm{g}$ \\
\hline Calcium & $468 \mathrm{mg}$ \\
\hline Phosphorus & $961 \mathrm{mg}$ \\
\hline Iron & $87.4 \mathrm{mg}$ \\
\hline lodine & $142 \mu \mathrm{g}$ \\
\hline Magnesium & $319 \mathrm{mg}$ \\
\hline Zinc & $1.45 \mathrm{mg}$ \\
\hline Selenium & $25.5 \mathrm{mg}$ \\
\hline Copper & $0.47 \mathrm{mg}$ \\
\hline Potassium & $1660 \mathrm{mg}$ \\
\hline Manganese & $3.26 \mathrm{mg}$ \\
\hline Sodium & $641 \mathrm{mg}$ \\
\hline
\end{tabular}

In view of its high protein content, spirulina may be a useful adjunct in the prevention and treatment of protein energy malnutrition (PEM) in children. In a study from Burkina Faso, the ingestion of $5 \mathrm{~g}$ spirulina together with traditional meals for 8 weeks was conducted on 84 HIV-infected and 86 HIV-negative children. The results showed on average, a weight gain of 15 and $25 \mathrm{~g} /$ day in HIV-infected and HIV-negative children, respectively. The level of anemia decreased during the study in all children. In which, $81.8 \%$ of HIVnegative undernourished children recuperated, while $63.6 \%$ of HIV-infected children responded ( $p=0.088$ ). These results suggested that spirulina may be a good food supplement for undernourished children. In particular, spirulina also seems to correct anemia and weight loss in HIV-infected children, and even more quickly in HIV-negative undernourished children [12]. A research study on 550 undernourished children $(<5 y)$ that provided an 8 week intervention on spirulina, Misola, spirulina plus Misola, or only traditional meals, showed that these interventions were good for undernourished children. However, the combination of spirulina and Mosola was better than the simple addition of protein and energy intake [13]

\section{Vitamin A Value of Spirulina}

Spirulina is rich in carotenoids with $\sim 50 \%$ occurring as $B$-carotene, a principal provitamin A carotenoid. As shown in Figure 1, HPLC analysis [14] indicates that 1 $\mathrm{g}$ of spirulina contains $0.9 \mathrm{mg}$ of all-trans $\beta$-carotene or $1.1 \mathrm{mg}$ of all-trans $\beta$-carotene equivalence, assuming that cryptoxanthin, 13-cis ß-carotene, and 9-cis $ß-$ carotene have half the activity of all-trans $\beta$-carotene. ß-carotene in spirulina, as in higher plants, is contained in chloroplasts and is associated with carotenoid binding proteins [15]. However, due to its simple matrix (unicellular), it is thought to be more digestible than leafy green vegetables such as spinach. Although the world production of spirulina reached 2,450 metric tons in 1999 [16] (Earth Food Spirulina, page 165), the study of the bioavailability of algal carotenoids and their vitamin $A$ value in humans is limited.

A study carried out in India in 1-6 yr old children ( $\mathrm{n}$ $=30$ ) given $1 \mathrm{~g}$ spirulina per day for 6 weeks showed significant improvements in hemoglobin, serum protein, and serum retinol levels [17] as compared to the control group ( $n=30$, given a placebo). Ninety percent of the children taking spirulina had significant increase in serum retinol, while the children in the control group showed no significant change in serum retinol. Another study conducted in Madagascar on 90 underweight children aged 4 - 5 years old found that one third of the children who consumed spirulina platensis daily for 21 days showed a $13 \%$ increase in the serum retinol 


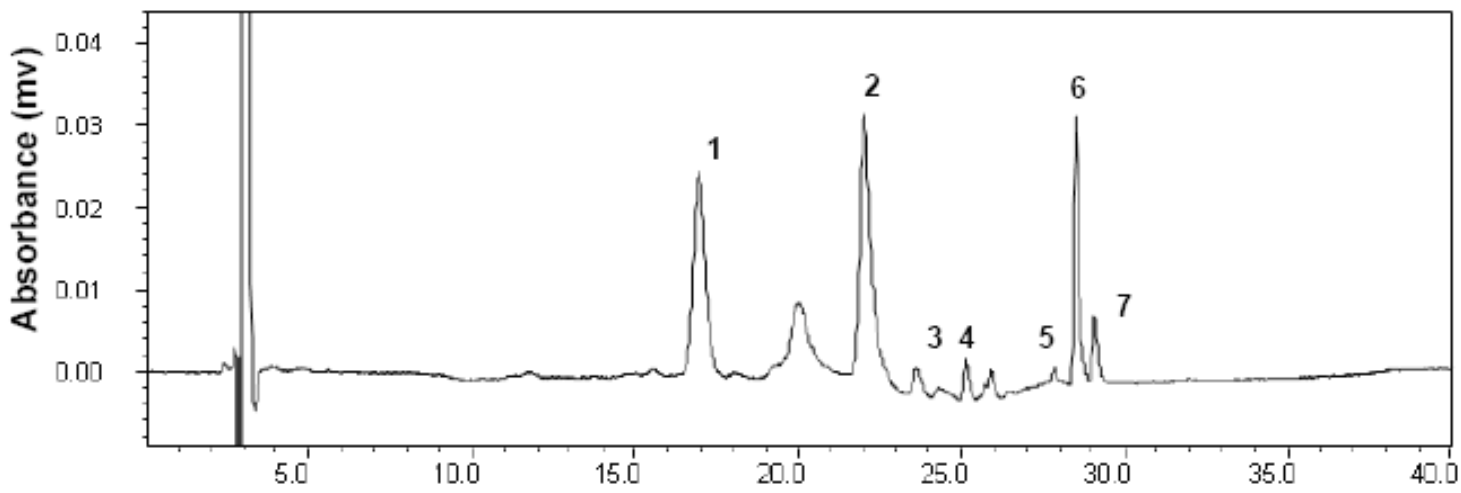

Time (min)

\section{Zeaxanthin; 2. Chlorophyll; 3. Chlorophyll; 4. Cryptoxanthin; 5. 13-cis $\beta$-carotene; 6. All-trans $\beta$-carotene; 7. 9-cis $\beta$-carotene. Other peaks are unknowns}

HPLC program used:

Carotenoids in spirulina were analyzed using a Waters HPLC coupled with a Waters 994 Programmable Photodiode Array Detector (Waters Corporation, Milford, MA) and a semi micro bore $C_{30}$ column $(3 \mu \mathrm{m}, 150 \mathrm{~mm} \times 3.0 \mathrm{~mm}$, YMC, Wilmington, NC).

The HPLC mobile phase A contained methanol, methyl tert-butyl ether (MTBE), and $1.5 \%$ ammonium acetate in water (85/12/3, v/v/v); and mobile phase $B$ contained methanol, MTBE, and 1.0\% ammonium acetate in water $(8 / 90 / 2, \mathrm{v} / \mathrm{v} / \mathrm{v})$.

The gradient procedure from $100 \%$ mobile phase $A$ to $95 \%$ mobile phase $B$, at a flow rate of $0.4 \mathrm{ml} / \mathrm{min}$, was as follows: $0 \% \mathrm{~B}$ isocratic $(0-3$ min), 0\% B - 20\% B linear gradient (3 - $18 \mathrm{~min}$ ), 20\% B - 55\% B linear gradient (18 -22 min), 55\% B - 95\% B linear gradient (22 - 33 min), $95 \%$ B (33 - 37min), 95\% B - 0\% B gradient (37 - $40 \mathrm{~min})$.

To extract carotenoids from spirulina, $1.0 \mathrm{mg}$ of dried spirulina powder was mixed with $10 \mathrm{ml}$ methanol for $1 \mathrm{~h}$ in a shaking incubator at $120 \mathrm{rpm}$. The mixture was centrifuged at $3000 \mathrm{rpm}$ for $5 \mathrm{~min}$, and the methanol extract was transferred into a 50 ml volumetric flask. The residue was further extracted with $10 \mathrm{ml}$ of THF, vortexed, and centrifuged at $3000 \mathrm{rpm}$ for $5 \mathrm{~min}$. Extraction of THF was repeated 3 to 4 times, and all THF extracts were combined with the methanol extract in the same flask. The final volume of the spirulina extract was adjusted to exactly $50 \mathrm{ml}$ in the volumetric flask, and $1 \mathrm{ml}$ of the extract was transferred to a $10 \mathrm{ml}$ glass tube, dried under nitrogen, and resuspended with $1 \mathrm{ml}$ of ethanol for HPLC and LC-APCI-MS analyses.

Figure 1: $\beta$-carotene and other Carotenoids in the extract of spirulina separated by using HPLC (equipped with C30 column) analysis (Bo et al, 2011, Br J Nutr. in press).

concentration and the prevalence of underweight (weight/age) had declined $10.5 \%$, while the wasting had disappeared [18].

It is obvious that there is a need to further evaluate the vitamin A value of spirulina. It is now possible to use advanced technologies to conduct human investigations by using intrinsically labeled spirulina. Spirulina can grow under heavy water to produce an intrinsically labeled product for human absorption and conversion studies [19]. A very recent report used a vitamin $A$ reference dose to determine the vitamin $A$ value of $\beta$-carotene from the spirulina grown hydroponically [20]. For the study, spirulina was grown in a 23 atom\% ${ }^{2} \mathrm{H}_{2} \mathrm{O}$ cultural solution. Ten healthy Chinese male subjects with a mean ( \pm SD) serum retinol concentration of $1.7 \pm 0.3 \mu \mathrm{mol} / \mathrm{L}$ and a BMI of $23 \pm 3 \mathrm{~kg} / \mathrm{m}^{2}$ consumed $5.8 \mu \mathrm{mol}$ of $\left[{ }^{13} \mathrm{C}_{10}\right]$ retinyl acetate in oil with a breakfast containing $13 \mathrm{~g}$ of fat as a reference dose. One week later, each subject consumed $7.9 \mu \mathrm{mol}$ of trans $\beta$-carotene in spirulina with a breakfast containing $22 \mathrm{~g}$ of fat. Low carotenoid and vitamin A diets were followed by all the subjects and forty blood samples were collected from each subject over 56 days. The concentrations and enrichments of retinol and $\beta$-carotene in serum samples were determined by using HPLC (high-performance liquid chromatography) and MS (mass spectrometry). The formation of labeled vitamin $A$ from the intrinsically labeled spirulina $\beta$-carotene was compared with a reference dose of known amount of vitamin $A$ that was labeled differently in these subjects. By using this 
reference method, the conversion factor of spirulina $\beta$ carotene to vitamin A was determined to be 4.5 to 1 (by weight) in adults [20].

The evaluation of the bio-efficacy of spirulina $\beta$ carotene provides a scientific basis for the possibility of using this algae to provide vitamin $A$ nutrition and to alleviate vitamin A deficiency in some areas of the world. Further determination of the absorption and conversion of spirulina $\beta$-carotene to vitamin $A$ in field settings with various age groups under various nutrition statuses is of great importance for eventually designing food programs in many regions of the world where vitamin A deficiency is common.

\section{Other Potential Biological Functions of Spirulina}

The possible biological function of spirulina supplements has been comprehensively reviewed by Belay [3] and in a recent book by Gershwin and Belay [4]. According to those sources, adding spirulina to meals has been reported to have favorable effects on glycemic control and lipid patterns, thus being of potential usefulness in the therapy of Diabetes mellitus Type II and in the control of cardiovascular risk factors [4]. There is a need to further understand the mechanism of these possibly favorable effects of spirulina.

Other very recent reports on spirulina research in human health are briefly highlighted as follows.

A human study reported [21] that a randomized double-blind, placebo-controlled experiment was conducted on 78 individuals aged 60-87 years who received either spirulina $8 \mathrm{~g}$ per day of spirulina or a placebo for 16 consecutive weeks. In male subjects, a significant plasma cholesterol-lowering effect was observed after the spirulina intervention $(p<0.05)$. Spirulina supplementation resulted in a significant rise in plasma interleukin (IL)-2 concentration, and a significant reduction in IL-6 concentration. A significant time-by-treatment intervention for total antioxidant status was observed between the spirulina and the placebo groups $(p<0.05)$. In female subjects, significant increases in IL-2 level and superoxide dismutase activity were observed $(p<0.05)$ after spirulina supplementation. There were significant reductions in the total cholesterol in female subjects. These results demonstrate that spirulina has favorable effects on lipid profiles, immune variables, and antioxidant capacity in healthy, elderly male and female subjects.
Another study enrolled 40 volunteers (male \& females $>50 \mathrm{y}$ ), who had no history of major chronic diseases [22]. Participants took a spirulina supplementation $0.5 \mathrm{~g}$ per day for 12 weeks and were administered comprehensive dietary questionnaires to determine their nutritional regimen during the study. Complete cell count (CCC) and indoleamine 2,3dioxygenase (IDO) enzyme activity, as a sign of immune function, were determined at baseline and weeks 6 and 12 of supplementation. Thirty study participants completed the entire study and the data obtained were analyzed. Over the 12-week study period, there was a steady increase in average values of mean corpuscular hemoglobin in subjects of both sexes. In addition, mean corpuscular volume and mean corpuscular hemoglobin concentration also increased in male participants. Older women appeared to benefit more rapidly from spirulina supplements. Similarly, the majority of subjects manifested increased IDO activity and white blood cell count at 6 and 12 weeks of spirulina supplementation. Spirulina may improve anemia status and immunosenescence in older subjects.

Spirulina also showed as an effective source to provide zeaxanthin (Figure 1, peak 1), a component also found in human macular [23]. Zeaxanthin is a predominant xanthophyll in human eyes and may reduce the risk of cataracts and age-related macular degeneration. Spirulina is an algal food that contains a high concentration of zeaxanthin. Single servings of ${ }^{2} \mathrm{H}$ labeled spirulina $(4.0-5.0 \mathrm{~g})$ containing $2.6-3.7 \mathrm{mg}$ of zeaxanthin were consumed by 14 healthy male volunteers (4 Americans and 10 Chinese) with $12 \mathrm{~g}$ dietary fat. Blood samples were collected over 45 days. Serum concentrations of total zeaxanthin were measured using HPLC and enrichment, and enrichment of labeled zeaxanthin was determined using LC-APCl-MS (liquid chromatography/ Atmospheric pressure chemical ionization). The results showed that intrinsically labeled spirulina zeaxanthin in the circulation was detected and a single dose of spirulina can increase mean serum zeaxanthin concentration in human subjects from 0.06 to 0.15 $\mu \mathrm{mol} / \mathrm{L}$ in American and Chinese volunteers. It is concluded that spirulina can serve as a rich source of dietary zeaxanthin which can effectively increase serum zeaxanthin concentration in humans.

These studies reveal that great attention and extensive studies have been devoted to evaluate the health benefits on reduce diseased conditions including hypercholesterolemia, hyperglycerolemia, cardiovascu- 
lar diseases, inflammatory diseases, cancer, and viral infections. The cardiovascular benefits of spirulina [24] are primarily resulted from its hypolipidemic, antioxidant, and anti-inflammatory activities. Data from human clinical trials are largely consistent with the hypolipidemic effects of spirulina observed in the preclinical studies. However, most of the human clinical trials are hampered by limited sample size and some by poor experimental design.

To have a clearer understanding on the use of spirulina, FAO (was requested by the UN General Assembly to prepare a draft position paper on spirulina entitled "A review on culture, production and use of spirulina as food for humans and feeds for domestic animals and fish" [25].

\section{CHLORELLA}

Chlorella is another alga that is high in protein content ( $60 \%$, providing most amino acids) and contains many vitamins and minerals. However, the cell wall of chlorella is rigid and indigestable. Because of this, harvested chlorella cells need to be processed in order to break the cell wall before using it as a dietary supplement for its nutrient content. The bioavailability of chlorella provitamin A carotenoids has not been tested in humans yet. Although there is a good amount of provitamin A carotenoids in this alga that could be converted to vitamin $A$ in humans, chlorella has an exceptionally high content of chlorophyll and is the source of most commercial chlorophyll [26].

\section{Vitamin B12 in Chlorella}

It is reported that 171 out of 326 algal species tested showed cobalamin auxotrophy [27]. For algae that are cobalamin auxotrophy, the source of cobalamin will be the interaction of algae with the bacteria or the added vitamin B12 in the growth medium. It was reported that freshwater chlorella (bacteria free condition) grown in a medium containing vitamin B12 can achieve the same level of vitamin B12 as that of marine chlorella has [28]. The nutritional value of the freshwater chlorella can therefore be improved.

Chlorella contains large quantities of folate, vitamin B-12 and iron, and can help improve anemia and hypertensive disorders. A recent study [29] investigated the preventive effects of chlorella supplements on anemia in Japanese pregnant women. During the study, a total of 70 pregnant Japanese women were placed into the control group $(n=38)$ or the chlorella group $(n=32)$. The subjects in the chlorella group were supplemented daily with $6 \mathrm{~g}$ of the chlorella supplement from the 12th-18th week of gestation until delivery. The proportion of anemic (hemoglobin level $<11 \mathrm{~g} / \mathrm{dL}$ ) subjects in the chlorella group were significantly lower than those in control group in the second and third trimesters. Additionally, in the chlorella group, the incidences of proteinuria and edema (signs of pregnancy-induced hypertension), were significantly lower during the third trimester. These results suggest that chlorella supplementation significantly reduces the risk of pregnancy associated anemia, proteinuria and edema. Chlorella supplement may be useful as a resource of natural folate, vitamin B-12 and iron for pregnant women [29].

\section{Other Health Effect}

Chlorella also contains Chlorella Growth Factor that can strengthen immunity and prevent or destroy cancer lesions. A recent report on a randomized, double-blind, placebo-controlled community-based clinical trial showed that, after feeding a $200 \mathrm{mg}$ or $400 \mathrm{mg}$ chlorella aqueous extract for 28 days, the antibody response among participants aged $50-55$ years increased [30]. Therefore, this algae extract may be useful as a dietary supplement for its immunoenhancing effect.

Also, a clinic trial [31] that used a daily dietary supplement of $10 \mathrm{~g}$ chlorella tablets and $100 \mathrm{ml}$ chlorella extract for 2 months showed that 6 out of 24 study subjects reduced their Sitting Diastolic Blood Pressure (from 90 to $115 \mathrm{mmHg}$ to less than $90 \mathrm{~mm}$ $\mathrm{Hg}$ ). Therefore, for some subjects with mild to moderate hypertension, a daily consumption of chlorella may reduce their blood pressure.

\section{DUNALIELLA}

Dunaliella is a genus of unicellar algae belonging to the family Polyblepharidaceae, that which lacks a rigid cell wall. This is a salt water alga and unlike spirulina and chlorella with high levels of proteins, it is very rich in mixed carotenes ( $\alpha$-carotene, all-trans $\beta$-carotene, 9 cis $\beta$-carotene, 9-, 15-dicis $\beta$-carotene, 15-cis $\beta$ carotene, and lycopene) and xanthophylls (zeaxanthin, lutein, $\alpha$ \& $\beta$-cryptoxanthin, violaxanthin, and echinenone) with an exceptionally high amount of 9-cis $\beta$-carotene [32, 33]. Dunaliella (Rhodophyta) provides the highest density of natural carotenoids of all the 
plants and algae. Thus, dunaliella provitamin A carotenes (located in the chloroplast) exhibit bright red color. While the provitamin A carotenoids of dunaliella are the highest among the three algae (as high as $13.8 \%$ of dry weight to be $\beta$-carotene) [34], the application of dunaliella has been focused in its pharmacological functions (antihypertentive, bronchodilator, etc.) [35] and its use as natural food colorants or as an additive to cosmetics. Recently, Betatene $®$ natural mixed carotenoids that are extracted from dunaliella salina algae have been approved by US FDA (United States Food and Drug Administration) as a US food color and Generally Recognized as Safe (GRAS) [36].

\section{Other Health Effect}

Dunaliella carotene can protect cells against oxidant and photo damage [37]. Dunaliella helps protect the mammary cells [38, 39] and the delaying the development of atherosclerosis in diabetic patients through the susceptibility to LDL oxidation [40]. It is also reported that dunaliella protected rats from acidinduced enteritis and may have a possible benefit to patients with Crohn' disease [41]. Dunalielia contains high levels of 9 -cis $\beta$-carotene. A study combining treatments of fibrate and 9-cis $\beta$-carotene-rich powder of the alga dunaliella bardawil showed improvement in the drug's effect on HDL-cholesterol levels. In an openlabeled first trial, 20 fibrate-treated men with plasma HDL-cholesterol levels below $40 \mathrm{mg} / \mathrm{dl}$ were given dunaliella [42] capsules, providing $60 \mathrm{mg} \beta$ carotene/day, containing all-trans and 9-cis $\beta$-carotene (1:1 ratio, w/w). During a double blind placebocontrolled second trial, 22 fibrate-treated patients participated. In this trial, 11 patients were treated with dunaliella capsules, and 11 patients were treated with $\beta$-carotene-deficient dunaliella (by exposing the dunaliella powder exposed to air for 2 weeks to destroy the $\beta$-carotene contents in the powder) capsules. Following 6 weeks of the dual treatment plasma HDLcholesterol increased by 24.5 and $12.7 \%$ in the first and second trials, respectively $(P=0.002$ and 0.012$)$. The results show that a combination treatment of fibrate and 9-cis $\beta$-carotene-rich dunaliella powder amplifies the effect of the drug on HDL-cholesterol levels.

\section{Safety of Using Algal Products}

The fact that spirulina has been traditionally consumed in Chad and Mexico suggests the harmlessness of consuming the alga as a food as long as it is cultivated with clean water and in a non-polluted environment. Any potential toxicity of spirulina has to be viewed from both the 1) innate toxicity of spirulina and 2) the "external" toxicity due to contamination during the cultivation and processing of the product. As of today, there is little high-quality scientific research data on the safety and toxicity of spirulina in humans. Most data is from animal and in vitro experiments and these are discussed in the following section. Extensive toxicological studies in an animal model showed no adverse effects after subchronic treatment [43]. Spirulina has been determined by US FDA as GRAS and this affirmed its use as an ingredient in foods. Chlorella has been used for human consumption for more than a half century. A recent report of a lack of toxicity study in rats, in which orally administered (gastric gavages) were given to rats with low $(2 \mathrm{~g})$, high, $2 x, 4 x$, and $8 x$ high dose (equivalent to low to 8 times of recommended therapeutic dose to humans) of chlorella per day for 15 - 30 day. The study confirmed the safety of consuming this alga [44]. Further, a toxicity study on dunaliella carotenoids, after a 90-day subchronic toxicity study was performed in F344 rats at dose levels of 0 (control), $0.63 \%, 1.25 \%, 2.5 \%$ and $5 \%$ in powdered basal diet [45] showed that organ weight measurement and histopathological observation revealed no toxicological changes.

Recently, several concerns regarding potential toxicity of blue-green alga (spirulina) have been raised. Algae do have a rather high-metal binding capacity for metals such as cadmium (CD2+), or others (Ni2+, $\mathrm{Cr} 3+, \mathrm{Cu} 2+)$ in the environment $[46,47]$. Theoretically, heavy metal toxicity might result from a high intake of these metals with spirulina. On the other hand, spirulina might elicit a protective effect for cadmium induced hepatotoxicity [48]. In addition, these algae can also be used as an indicator of water quality as growth stops in contaminated water, eventhough the algae cannot improve the quality of water. The janus potentials of spirulina demonstrated the importance of assuring the cultivation of spirulina in clean noncontaminated water and containers to produce a safe product. More research in safe culture techniques for these promising algae is needed [49].

Spirulina related toxicity in the form of acute rhabdomyolysis was described in a young man consuming spirulina supplements [50]. Rhabdomyolysis has a wide differential diagnosis, and the spirulina ingestion could have been by an unrelated causal relation. In another study, spirulina has been shown to have musculo-protectivity in the setting of 
exhaustive incremental exercise testing [51]. In addition, any toxicity of spirulina might be related to contaminants. This underlines the importance of improving and studying different cultivation techniques which might be most suitable for "home growing" of spirulina as a vitamin A or protein source. Often, cynobacterial toxins are stemmed from toxic species when harvesting algae from mixed phytoplankton populations [4].

Nevertheless in view of the increasing consumption of spirulina as well as the suggested use of spirulina to reduce vitamin A malnutrition, any potential toxicity issues should be taken seriously. Based on the presently available data, it can be concluded that spirulina platensis bears no toxicity if cultivated properly and not consumed in excessive amounts. Similarly, the consumptions of chlorella and products of dunaliella are not harmful for human consumption as dietary supplements, food additive, or food colorant etc. It should be noted that in the past, studies evaluating the nutritional effect and value of spirulina to improve the status of certain nutrients often used poor methodology. Therefore, no final statement about the safety, efficiency and efficacy of spirulina can be made at the present time. Spirulina as a nutritional supplement is promoted as a panacea for many conditions and diseases and is now widely sold in the health food market. Nevertheless, the extensive use in higher amounts should be discouraged until more studies can be performed that will prove its safety and efficiency.

\section{REFERENCES}

[1] Borowitzka MA. Commercial production of microalgae: ponds, tanks, tubes, and fermenters. J Biotech 1999; 70: 313-21.

http://dx.doi.org/10.1016/S0168-1656(99)00083-8

[2] Lee Y-K. Commercial production of microalgae in the AsiaPacific rim. J Applied Phycology 1997; 9: 403-11. http://dx.doi.org/10.1023/A:1007900423275

[3] Belay A. The potential application of spirulina (arthrospira) as a nutritional and therapeutic supplement in health management. J Am Nutriceutical Association 2002; 5: 27-48.

[4] Gershwin ME, Belay A. Spirulina in human nutrition and health. CRC Press, Boca Raton, FL, USA, 2000.

[5] Halidou DM, Degbey H, Daouda H, Leveque A, Donnen P, Hennart $\mathrm{P}$, et al. The effect of spiruline during nutritional rehabilitation: systematic review. Rev. Epidemiol Sante Publique 2008; 56: 425-31. [Article in French] Source: Pédiatrie A, hôpital National de Niamey, BP 238, Niamey, Niger.mhalidou2002@yahoo.fr

[6] Ciferri O. Spirulina, the edible microorganism. Microbiological Reviews 1983; 47: 51-578.

[7] Watanabe F, Takenaka S, Kittaka-Katsura H, Ebara S, Miyamoto E. Characterization and bioavailability of vitamin
B12-compounds from edible algae. J Nutr Sci Vitaminol (Tokyo) 2002; 48: 325-31.

http://dx.doi.org/10.3177/jnsv.48.325

[8] Watanabe F,Miyamoto E, Fujita T, Tanioka Y,Nakano Y Characterization of corrinoid compound in the edible (bluegreen) alga, suizenji-nori. Biosci Biotechnol Biochem 2006; 70: 3066-8.

http://dx.doi.org/10.1271/bbb.60395

[9] Clément G, Giddey C. Amino acid composition and nutritive value of the alga spirulina maxima. $\mathrm{J}$ of the Science of Food and Agriculture 1967; 18: 497-501.

http://dx.doi.org/10.1002/jsfa.2740181101

[10] Becker EW. Micro-algae as a source of protein. Biotechnology Advance 2007; 25: 207-10. http://dx.doi.org/10.1016/j.biotechadv.2006.11.002

[11] Li D-M, Qi Y-Z. Spirulina industry in China: Present status and future prospects. J Appl Phycology 1997; 9: 25-8.

[12] Simpore J, Zongo F, Kabore F, Dansou D, Bere A, Nikiema $\mathrm{J}-\mathrm{B}$, et al. 2005. Nutrition rehabilitation of HIV-infected and HIV-negative undernourished children utilizing spirulina. Ann Nutr Metab 2005; 49: 373-80. http://dx.doi.org/10.1159/000088889

[13] Simpore J, Kabore F, Zongo F, Dansou D, Bere A, Pignatelli $\mathrm{S}$, et al. Nutrition rehabilitation of undernourished children utilizing Spiruline and Misola. Nutrition Journal 2006; 5: 3. http://dx.doi.org/10.1186/1475-2891-5-3

[14] Yeum KJ,Booth SL,Sadowski JA, Liu C, Tang G, Krinski NI, et al. 1996. Huamn plasma carotenoid response to the ingestion of controlled diets high in fruits and vegetables. Am J Clin Nutr 1996; 64: 594-602.

[15] Goodwin TW. The biochemistry of carotenoids. London \& New York: Chapman and Hall. 1980.

[16] Earth Food Spirulina, Available from: http://www.spirulinasource.com/PDF.cfm/ EarthFoodSpirulina.pdf

[17] Thinakar V, Edwin N. Spirulina - a nutrition booster. Study paper presented at the 7th World Congress on Clinical Nutrition, 14-17 October 1999, New Delhi, India (mimeo).

[18] Razafiarisoa B, Ramaroson E, Ramampiherika D. 2004 Using spirulina platensis to reduce vitamin A deficiency in Malagasy children. International Vitamin A Consultative Group Meeting XXII, Lima, Peru. Abstract M20, Page 33, 2004.

[19] Gireesh T, Jayadeep A, Rajasekharan KN, Menon VP, Vairamany $M$, Tang $G$, et al. Production of deuterated $\beta$ carotene by metabolic labelling of spirulina platensis. Biotech Letters. 2000; 23(6): 447-9.

http://dx.doi.org/10.1023/A:1010378401621

[20] Wang J, Wang Y, Wang Z, et al. 2008. Vitamin A equivalent of spirulina $\beta$-carotene in Chinese adults as assessed by stable isotope dilution and reference techniques. Am J Clin Nutr 2008; 87: 1730-7.

[21] Park HJ, Lee YJ, Ryu HK, Kim MH, Chung HW, Kim WY A randomized double-blind, placebo-controlled study to establish the effects of spirulina in elderly Koreans. Ann Nutr Metab 2008; 52: 322-8. http://dx.doi.org/10.1159/000151486

[22] Selmi C, Leung PSC, Fischer L, German B, Yang C-Y, Kenny TP, Cysewski GR,and Gershwin ME. The effects of spirulina on anemia and immune function in senior citizens. Cellular \& Molecular Immunology 2011; 8: 248-54. http://dx.doi.org/10.1038/cmi.2010.76

[23] Yu B, Wang J, Suter PM, Russell RM, Grusak MA,Wang Y, et al. Spirulina is an effective dietary source of zeaxanthin to humans. Br J Nutr. 2011; in press.

[24] Deng R, Chow TJ. Hypolipidemic, antioxidant, and antiinflammatory activities of microalgae spirulina. Cardiovasc Ther 2010; 28: e33-45. 
[25] FAO Fisheries and Aquaculture Circular C1034, A review on culture, production and use of spirulina as food for humans and feeds for domestic animals. 2009; Available from: ftp://ftp.fao.org/docrep/fao/011/i0424e/i0424e00.pdf

[26] http:/www.sanchlorel/lansa.com/analysis-value-table.html

[27] Croft MT, Lawrence AD, Raux-Deery E, Warren MJ, Smith AG. Algae acquire vitamin B12 through a symbiotic relationship with bacteria. Nature. 2005; 438: 90-3.

[28] Hirayam K, Maruyama I, and Maeda T. Nutritional effect of freshwater chlorella on growth of the rotifer Brachionus plicatili. Hydrobiologia 1989; 186/187: 39-42.

http://dx.doi.org/10.1007/BF00048894

[29] Nakano S, Takekoshi H, Nakano M. 2010. Chlorella pyrenoidosa supplementation reduces the risk of anemia, proteinuria and edema in pregnant women. Plant Foods Hum Nutr 2010; 65: 25-30. http://dx.doi.org/10.1007/s11130-009-0145-9

[30] Halperin SA, Smith B, Nolan C. Nolan C, Shay J, Kralovec J. Safety and immunoenhancing effect of a chlorella-derived dietary supplement in healthy adults undergoing influenza vaccination: randomized, double-blind, placebo-controlled trial. CMAJ 2003; 169: 111-7.

[31] Merchant RE, Andre CA,Sica DA. 2002. Nutritional supplementation with chlorella pyrenoidosa for mild to moderate hypertension. J Medicinal Foo.2002; 5: 141-52. http://dx.doi.org/10.1089/10966200260398170

[32] Ben-Amotz A, Levy Y. Bioavailability of a natural isomer mixture compared with synthetic all-trans $\beta$-carotene in human serum. Am J Clin Nutr 1969; 63: 729-34.

[33] Suzuki T, Nakashima M, Ohishi N. Kunio Y. A simple procedure for large-scale purification of 9-cis $\beta$-carotene from dunaliella bardawil. Biochem \& Molecular Biology International 1996; 39: 1077-84.

[34] Aasen AJ, Eimhjellen KE, Liaaen-Jensen S. An extreme source of $\beta$-carotene. Acta Chem Scand 1969; 23:2544-5. http://dx.doi.org/10.3891/acta.chem.scand.23-2544

[35] Borowitzka MA. Microalgae as sources of pharmaceuticals and other biologically active compounds. J Applied Phycology 1995; 7: 3-15. http://dx.doi.org/10.1007/BF00003544

[36] Cognis Nutrition and Health, 2009. Available from: http://www.foodingredientsfirst.com/product-by-sector/ Colours/Cognis-Mixed-Carotenoids-Product-Now-GRAS.html

[37] Jiménez $C$, and. Pick U. Differential reactivity of $\beta$-carotene isomers from dunaliella. bardawil toward oxygen radicals. Plant Physiol 1993; 101: 385-90.

[38] Fujii $Y$, Sakamoto S, Ben-Amotz A, Nagasawa H. Effects of $\beta$-carotene-rich algae dunaliella bardawil on the dynamic changes of normal and neoplastic mammary cells and general metabolism in mice. Anticancer Res 1993; 13: 38993.

[39] Nagasawa H, Fujii Y, Kageyama Y, Segawa T, Ben-Amotz A Suppression by $\beta$-carotene-rich algae dunaliella bardawil of the progression, but not the development, of spontaneous mammary tumours in SHN virgin mice. Anticancer Res 1991; 11: 713-7.

[40] Levy $\mathrm{Y}$, Zaltsberg H, Ben-Amotz A, Kanter $\mathrm{Y}$, Aviram M. Dietary supplementation of a natural isomer mixture of $\beta$ carotene inhibits oxidation of LDL derived from patients with diabetes mellitus. Ann Nutr Metab 2000; 44: 54-60. http://dx.doi.org/10.1159/000012821

[41] Lavy A, Naveh Y, Coleman R, Mokady S, Werman MJ.Dietary Dunaliella bardawil, a $\beta$-carotene-rich alga, protects against acetic acid-induced small bowel inflammation in rats. Inflamm Bowel Dis 2003; 9:372-9. http://dx.doi.org/10.1097/00054725-200311000-00005

[42] Shaish A,Harari A, Hananshvili L, Cohen H, Bitzur R, Luvish $\mathrm{T}$, et al. 9-cis $\beta$-carotene-rich powder of the alga dunaliella bardawil increases plasma HDL-cholesterol in fibrate-treated patients. Atherosclerosis 2006; 189: 215-21.

http://dx.doi.org/10.1016/j.atherosclerosis.2005.12.004

[43] Salazar M, Martinez E, Madrigal E, Ruizhttp://www.sciencedirect.com/science/article/pii/S037887 4198000804 - AFF3 LE, Chamorro GA. Subchronic toxicity study in mice fed spirulina maxima. J Ethnopharmacology 1998; 62: 235-41.

[44] Final report, Preclinical toxicity of chlorella vulgaris E-25 acute and subacute studies in Fisher strain of rats. 2000 Available from: http://icmr.nic.in/final/final nin.pdf

[45] Kuroiwa $Y$, Nishikawa A,Imazawat T, Kitamura Y, Kanki K Ishii $\mathrm{Y}$, et al. A subchronic toxicity study of dunaliella carotene in F344 rats. Food Chem Toxicol 2001; 44: 138-45. http://dx.doi.org/10.1016/j.fct.2005.06.010

[46] Doshi H, Ray A, Kothariz IL. Biosorption of cadmium by live and dead spirulina: IR spectroscopic, kinetics, and SEM studies. Current Microbiology 2007; 54: 213-8. http://dx.doi.org/10.1007/s00284-006-0340-y

[47] Cain A, Vannel R, Woo LK. Cyanobacteria as a biosorbent for mercuric ion. Bioresource Technology 2008; 99: 6578-86. http://dx.doi.org/10.1016/j.biortech.2007.11.034

[48] Karadeniz A, Cemek M, Simsek N. The effects of Panax ginseng and spirulina platensis on hepatotoxicity induced by cadmium in rats. Ecotoxicology and Environmental Safety 2009; 72: 231-5 http://dx.doi.org/10.1016/j.ecoenv.2008.02.021

[49] Kim C-J, Jung Y-H, Ko S-R, Kim H-I, Park Y-H, Oh H-M. Raceway cultivation of spirulina platensis using underground water. J Microbiol Biotechnol 2007; 17: 853-7.

[50] Mazokopakis EE, Karefilakis CM, Tsartsalis AN, Milkas AN, Ganotakis ES. Acute rhabdomyolysis caused by spirulina (Arthrospira platensis). Phytomedicine 2008; 15: 525-7. http://dx.doi.org/10.1016/i.phymed.2008.03.003

[51] Lu H-K, Hsieh C-C, Hsu J-J, Yang Y-K,Chou H-N. Preventive eVects of spirulina platensis on skeletal muscle damage under exercise-induced oxidative stress. Eur J Appl Physiol 2006; 98: 220-6.

http://dx.doi.org/10.1007/s00421-006-0263-0

\section{DOI: http://dx.doi.org:10.6000:1927-5951.2011.01.02.04}

(C) 2011 Tang and Suter; Licensee Lifescience Global.

This is an open access article licensed under the terms of the Creative Commons Attribution Non-Commercial License (http://creativecommons.org/licenses/by-nc/3.0/) which permits unrestricted, non-commercial use, distribution and reproduction in any medium, provided the work is properly cited. 